\title{
Changing medical practices in Venezuela: Gis at war medicine practice without a war
}

\section{Opinion}

The otherwise proud country with state of the art gastroenterology units is vanishing step by step. In the last three years, mayor representatives of endoscopy industries or have flee the country because security reasons, the lack of equipments to sell as well as endoscopes spare parts doesn't arrive. Same happened with the companies of ancillary equipments. Very few units in the private sector can now perform all standards diagnostic and therapeutic procedures, including enteroscopy, capsule, endoscopic ultrasound, prosthesis, biliary procedures.

How long this private gastroenterology units shall last in their practices?

In a country with extremely distorted economy, inflation rate 2015 of $180 \%$ and possible 2016 over $700 \%$ there is no an effective way of planning.

What we have had see in the public sector is a complete degradation of actual standard practices. E.g. Upper digestive hemorrhage primary surgically treated because the lack of functional endoscopes or lack of the ancillary equipment. No availability of interventional radiology as well as overwhelm ICU without essential medications such as atropine or adrenaline give ominous results not only to GI patients.

Desnutrition in children and in adults, the appearance of old maladies as malaria now are extended to $15 \%$ o more states in the country. There is no antiprotozals or anthelminthic drugs for more of a year. High cost medicines for hepatitis or inflammatory bowel disease are disappear or erratic supply as well the anti-inflammatory drugs such as prednisone only is commonly found for veterinary use.

So medical practice, for paediatricians and internist in gastroenterology working at public hospitals place them like doctors at war suffering lack of support of other units, departments, services and the lack of medicines. Medicines stocks are report to be in or around $20 \%$ of normal inventory country wide. Reports of shutdown
Volume 6 Issue 5 - 2017

Roman Bacalao Romer

Department of Gastroenterology, Universidad Central de Venezuela, Venezuela

Correspondence: Roman Bacalao-Romer, Hospital Privado Centro Medico de Caracas Former Assistant Professor in Gastroenterology, Universidad Central de Venezuela, Venezuela, Email romanbacalao@hotmail.com

Received: October 31, 2016 | Published: April 17, 2017

of public OR to levels never seeing previously because lack of anesthesia, surgeons, anaesthesiologists or laboratory tests.

This humanitarian crisis is not recognized by the present government administration. So the future is grim at this time and directors of public and private endoscopy units have very different ways to cope this situation. Those differences are related how to manage the crisis, this not about science, medicines or equipment, not even about predict cost in hyper inflationary situation, but instead represents the anti-medical practice, with a false dilemma or double standard: those who can afford it versus those who not because depend of public funds. This immoral situation seats everyone to cry their wares. There is no official information of morbidity and mortality as part of the information darkness, we only depend on partial reports of different medicals association.

\section{Acknowledgments}

None.

\section{Conflicts of interest}

The author declares there is no conflict of interest. 